\title{
CRESCIMENTO URBANO E CONSEQUÊNTES INUNDAÇÕES NA CIDADE DE PRESIDENTE PRUDENTE: ESTUDO DE CASO PARQUE DO POVO
}

Lennon Gomes; Marciel Roberto Encenha'; Mayara Pissutti Albano²; Yeda Ruiz Maria².

${ }^{1}$ Discente do curso de Arquitetura e Urbanismo da Universidade do Oeste Paulista - UNOESTE. ${ }^{2}$ Docente do curso de Arquitetura e Urbanismo da Universidade do Oeste Paulista - UNOESTE.

\section{RESUMO}

Este artigo busca fazer uma análise sobre crescimento urbano de cidades médias, tendo como objeto de estudo Presidente Prudente, localizada no interior do Estado de São Paulo, considerando questões ambientais, infraestrutura e o ambiente construído. Objetiva-se o discutir a relação entre o crescimento urbano acelerado e parte das problemáticas relacionadas a inundações, ocorridas na região do Parque do Povo, que colocam em risco a saúde pública, provocam danos ao patrimônio público e privado, causam acidentes de trânsito. Também acarretam em prejuízos aos cofres públicos que têm que arcar com os danos causados. A metodologia foi baseada em pesquisas bibliografias e documentais relacionadas ao tema.

Palavras-chave: Inundações; Parque do Povo; planejamento urbano ambiental; crescimento urbano acelerado.

\section{INTRODUÇÃO}

Este artigo visa a analisar a cidade de Presidente Prudente - SP, discutindo os efeitos do crescimento desordenado consequente da ausência de um planejamento urbano ambiental, resultando na presença de grandes vazios no traçado da cidade.

O processo de expansão urbana ocorrido em Presidente Prudente até o final da década de 1960 não teve regulação urbanística ou normatização legal, a ampliação da malha urbana não tinha relação direta com o crescimento populacional e econômico da cidade, e foi incentivado pelo mercado imobiliário que pretendia lucrar com a valorização de terras baratas e algumas áreas irregulares (HONDA, 2011).

O projeto do Parque do Povo surgiu mediante interesses políticos, que ficam claros pelos investimentos feitos em uma área que era considerada degradada e que recebeu grandes obras de infraestrutura e abertura de duas vias rápidas e desapropriação de boa parte da população local (cerca de trezentos e trinta proprietários) (SILVA, 1994).

O local possui infraestrutura de escoamento precária, acentuada impermeabilização do solo e vazões de escoamento insuficientes, conforme apontou o Centro Tecnológico de Hidráulica (CTH) da Universidade de São Paulo, fatos que agravam a problemática das enchentes em épocas de precipitações. Estudos relacionados ao Parque do Povo, como, por exemplo Vaz, (1999), 
apontam a ausência de matas ciliares e os riscos de enchentes dinamizados pela canalização do Córrego do Veado, fato que esconde o mesmo e a poluição das cidades.

Na cidade de Presidente Prudente, a frequência de maiores precipitações esta entre o mês de Outubro a Março, a ocorrência de transbordamentos em vários pontos da cidade, revelava o sub-dimensionamento do sistema de drenagem urbana. Outros fatores como ausência de matas ciliares, assoreamentos, que aliados a questão de lixos e entulhos, faz o córrego sair de seu leito natural, e somados a excessiva impermeabilização do solo, que aumenta o escoamento superficial, provoca as inundações (VAZ, 1999).

O objetivo deste trabalho é relacionar o crescimento urbano acelerado, impermeabilização do solo, canalização de córrego e outros fatores, ao surgimento de inundações frequentes na cidade como um todo, com abordagem focada no caso do Parque do Povo em Presidente Prudente - SP, que trás prejuízos financeiros ao Município e cidadãos, além de riscos ambientais, à saúde humana, ao sistema de escoamento e infraestrutura.

\section{METODOLOGIA}

A metodologia seguida foi baseada no aprofundamento bibliográfico e documental sobre o histórico de Presidente Prudente, a criação do Parque do Povo, inundações urbanas e problemas decorridos pelo sub-dimensionamento da infraestrutura urbana.

\section{BREVE HISTÓRICO DA FORMAÇÃO DE PRESIDENTE PRUDENTE}

A origem de Presidente Prudente está diretamente relacionada com a marcha do café em direção ao "sertão" do Estado de São Paulo (WHITACKER, 1997). Em 1917 formou-se o núcleo urbano de Presidente Prudente, em 1919, sua ocupação foi intensificada pela construção da estrada de Ferro da Alta Sorocabana.

Os primeiros proprietários começaram a lotear e vender parte de suas propriedades para a formação de núcleos urbanos e médias propriedades rurais. Em função da inexistência de capital necessário para o incremento de sua produção, acabaram surgindo pequenas indústrias de beneficiamento e comercialização (CUNHA; ARANHA, 1992).

Os dois primeiros loteamentos foram constituídos por Goulart e Marcondes. De forma diversa à de Goulart, o Cel. José Soares Marcondes. Ainda nos primeiros anos, a Vila Goulart assumiu o papel de centro comercial e área residencial das famílias de maior poder monetário, enquanto a Vila Marcondes passou a atrair as empresas de beneficiamento agrícola ao longo da 
linha ferroviária e bairro residencial das classes de menor poder monetário (HONDA, 2011), como a S/A IRF Matarazzo e Anderson Clayton e Co. S/A., que se instalaram nestas terras entre os anos 1935 e 1945 (SILVA, 2005).

Entre a década de 1920 e primeira metade da de 1950, a cidade se expandiu significativamente, porém, sem planejamento e sem regularização legal. A informalidade na organização fundiária do território atingiu diretamente a produção da cidade, que atravessou períodos com grande expansão da malha urbana (HONDA, 2011).

Entre as décadas de 1960 e 1970, percebe-se aumento da população, ampliação do quadro industrial, com desvinculação da produção agrícola local, como aponta Honda (2010), e um desenvolvimento das atividades terciárias.

Na década de 1970, o modelo chamado "político-empresárial" passou a compor o cenário político de Presidente Prudente. Desta feita, consolidou-se o discurso desenvolvimentista que enfatizava a promoção da indústria visando o pleno desenvolvimento econômico, social e cultural para o município. Este fenômeno fez parte de um movimento nacional de impulsão à industrialização (DUNDES, 2001).

A expansão urbana durante as duas décadas seguintes, 1970 e 1980, ocorreu sem precedentes, porém, com mais ênfase na direção sudoeste, gerando grandes vazios no traçado da cidade, por grandes períodos de tempo. Pode-se afirmar que a malha urbana praticamente dobrou nesse período (HONDA, 2011), É na direção sudoeste da cidade onde está localizado o Parque do Povo, objeto de estudo desta pesquisa.

\section{ESTUDO DE CASO: PARQUE DO POVO}

O Parque do Povo surgiu da "urbanização" do fundo de vale do Córrego do Veado no trecho da Avenida Brasil à Avenida Manoel Goulart, sentido NW - SE (ver Figura 1), juntamente com a aplicação de infraestrutura, na área até então degradada. As obras tiveram início em 31 de outubro de 1976 (SILVA, 1994). A área de abrangencia do projeto era de apoximadamente 460 mil $\mathrm{m}^{2}$. E incluia, além da canalização de um trecho do Córrego do Veado, a instalação de equipamentos de lazer, pista de atletismo, serviços, duas vias de transito rápido e áreas verdes (BORTOLO, 2012).

Foi inaugurado em 1982, com a execução de apenas uma parte do projeto inicial. Mas foi o suficiente para provocar significativas alterações na ocupação urbana, como exemplo, a valorização das áreas adjacentes ao Parque, especulação imobiliária, desapropriação dos 
moradores do local, criação de vias de acessos, entre outras mudanças. Silva (1994), afirma que tais obras repercutiram em uma valorização das áreas adjacentes, e desta forma, acentuando o processo de segregação espacial e um estimulando a abertura de novos loteamentos de nível socioeconômico elevado, tornando-se um reprodutor de capital.

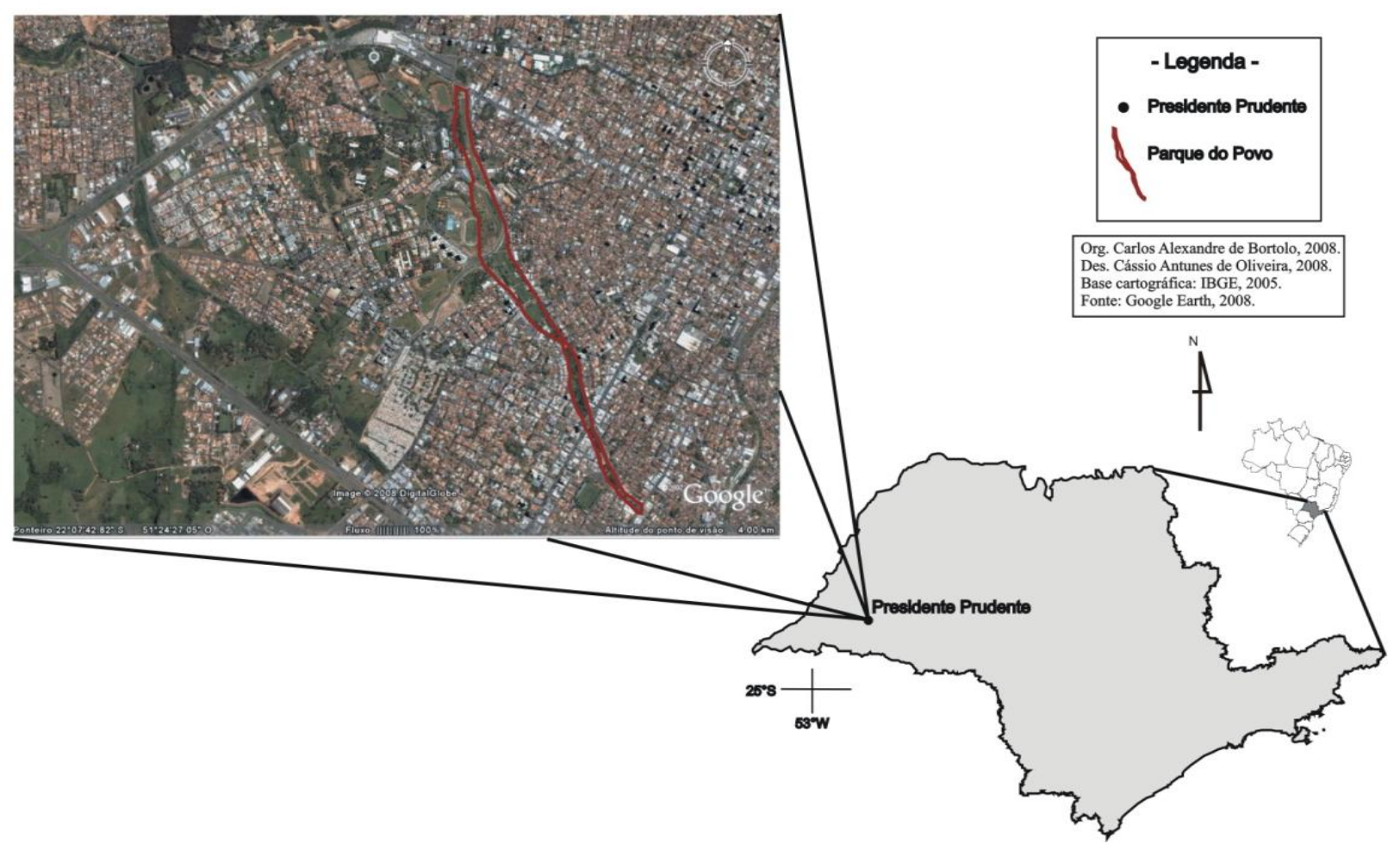

Figura 1. Localização Parque do Povo em Presidente Prudente Fonte: Google Earth, 2008. Organização: (Bortolo, 2008).

Segundo Silva (1994) os recursos utilizados eram de ordem pública, vindos num primeiro momento, do Fundo de Desenvolvimento Urbano (FDU) - repassados pelo Banco do Brasil - e do Departamento Nacional de Obras e Saneamento (DNOS). A partir do ano de 1977, os recursos vieram do Programa de Complementação Urbana CURA - Comunidade Urbana para Recuperação Acelerada (ARANA, et al, 2012).

O projeto do Parque do Povo foi de importância significativa à expansão urbana e desenvolvimento da cidade de Presidente Prudente, pois, com a construção das duas vias que o circundam, foi possível melhorar o sistema de circulação da cidade e se constitui uma importante área de lazer. No entanto, a política adotada no processo de desenvolvimento do projeto, com expropriação e elitização da área com grande aporte financeiro e investimentos com recursos públicos, fomentou a segregação socioespacial de Presidente Prudente (SILVA, 1994). 
Inicialmente a canalização do Córrego do Veado na extensão do Parque do Povo, se deu pela forma trapezoidal aberta, que foi posteriormente substituída por tubos em arcos (VAZ, 1999).

A canalização dos córregos, principalmente a canalização fechada, além de aumentar os riscos de enchentes e inundações nos fundos de vales, esconde o córrego e a poluição provocada pelas atividades humanas [...] (PIVA, 1999 apud VAZ, 1999, p.23).

Desde 1996, as precipitações já se mostravam preocupantes, pela incidência de inundações pela cidade de Presidente Prudente. Em 1997 e 1998, a Fundação Centro Tecnológico de Hidráulica (CTH) da Universidade de São Paulo elaborou um laudo hidrológico na cidade, principalmente sobre as áreas do Parque do Povo e Prudenshopping, propondo algumas soluções para a vazão de água necessária do local para solucionar a problemática de inundações (VAZ, 1999).

As maiores ocorrências de inundações na cidade de Presidente Prudente foram nos anos de 1994, duas ocorrências em 1996 e outra em 1998 (VAZ, 1999). Outras ocorrências mais recentes como, por exemplo, em 2007 (PREFEITURA DE PRESIDENTE PRUDENTE, 2007), 2012 (SPTV-2, 2012) e 2013 (FOGLIA; MATHIAS, 2013).

O levantamento realizado pela CTH indicou que na área do Parque do Povo possui $80 \%$ de solo impermeabilizado, fato que gera uma sobrecarga no sistema de escoamento pluvial intensificado pelas poucas vazões encontradas nestas áreas, além da topografia que direciona o escoamento ao Parque do Povo, visto que se trata de fundo de vale, causando assim as inúmeras inundações (VAZ, 1999).

Como afirma Binder (2001), por um longo período de tempo, a estratégia da engenharia fluvial e hidráulica esteve pautada em retificar o leito dos rios e córregos, para que suas vazões fossem dirigidas para jusante pelo caminho mais curto e com a mais alta velocidade de escoamento possível. Entre outros, um dos principais objetivos destas ações eram ganhar mais terra para a urbanização e diminuir os efeitos locais das cheias. No caso do Parque do Povo, o projeto Municipal objetivava melhorar a mobilidade urbana através da integração dos dois lados do Córrego do Veado, tendo como meio, a canalização do córrego por toda a extensão do parque. O ideal, como afirma Vaz (1999) seria que o Córrego do Veado preservasse suas matas ciliares, sem receber canalização. 
Os problemas enfrentados pela inundação do parque do povo tem por consequências o risco à saúde pública, danos ao patrimônio público e privado, interferências no trânsito e maior custo ao município que necessita arcar com os danos.

A conscientização das interações entre as atividades antrópicas e o meio ambiente permite, novas estratégias dirigidas à renaturalização de rios e córregos, valorizando as condições naturais dos cursos hídricos e das baixadas inundáveis. É evidente que esta concepção tem os seus limites, quando se trata de manter a proteção das zonas urbanas e das vias de transporte (BINDER, 2001, p. 5).

É no início do planejamento urbano onde os diferentes interesses relacionados à proteção à do meio ambiente natural e construído e também os interesses relativos aos usos específicos da água e de áreas de baixada devem ser levados em consideração, através da participação direta e intesa da sociedade civil (BINDER, 2001), no caso do Parque do Povo, o interesse financeiro se mostrou mais explícito e não foi inserido em diretrizes de um planejamento ambiental prévio que deveria conter esse tipo de ação que provocou inúmeras repercussões sociais e ambientais.

Se tratando da maior área de lazer da cidade de Presidente Prudente, a importância da problemática é significativa para a população e ao poder público, pois se trata da imagem da cidade e da responsabilidade do bem-estar de seus cidadãos. Segundo Binder (2001), o ideal para áreas como a do Parque do Povo seria a renaturalização do córrego, pois assim existiria grande possibilidade de evitar prejuízos para a população e oferecer compensações por eventuais desvantagens para certos usos (BINDER, 2001).

\section{CONSIDERAÇÕES FINAIS}

Presidente Prudente mostrou incentivo a expansão urbana, logo no início de sua formação, e continuou a fomentar o rápido processo de urbanização pelos fatos históricos ocorridos principalmente na década de 1920 a 1940, até a década de 1960.

Este processo de crescimento acelerado contribui de maneira negativa para desenvolvimento da cidade e para sua população, agravado pela ausência de um planejamento urbano ambiental.

$\mathrm{Na}$ área onde se situa o Parque do Povo, as inundações nos períodos de chuva são uma realidade, e se agravam em função de falhas na previsão de uma demanda maior de escoamento superficial da área em questão, além da retirada das matas ciliares, a questão do lixo urbano e 
desrespeito ao meio ambiente tornam a problemática mais frequente, colocando em risco a saúde pública.

Como afirma Binder (2001), a renaturalização de rios e córregos não significa a volta a uma paisagem original não influenciada pelo homem, mas visa o desenvolvimento sustentável dos rios e da paisagem em conformidade com as necessidades e conhecimentos contemporâneos. Pode-se concluir que os problemas de inundações ocorridos na região do Parque do Povo em Presidente Prudente necessitam de atenção e de um Planejamento para que os problemas sociais e ambientais ocorridos nesta área possam ser mitigados. Desta feita, a renaturalização do Córrego d Veado seria uma possibilidade a ser estudada em função dos inúmeros benefícios que poderia trazer à cidade de Presidente Prudente.

\section{REFERÊNCIAS}

ARANA, A. R. A. ; TAKENAKA, E. M. M. ; FELICIO, M. J. ; LUVIZOTTO, C. K. ; MARIA, Y. R. ; BIZARRO, L. M. C. E. ; ALBANO, M. P. Saúde, lazer, e qualidade urbana ambiental: um estudo sobre o parque do povo. In: IV CONGRESSO INTERNACIONAL DE GEOGRAFIA E SAÚDE, v. 4, 2012, Presidente Prudente - SP. Anais do IV Congresso Internacional de Geografia e Saúde, 2012.

BINDER, Walter. 2001. Rios e Córregos, Preservar - Conservar - Renaturalizar: A Recuperação de Rios, Possibilidades e Limites da Engenharia Ambiental. Disponível em: <http://www.pm.al.gov.br/intra/downloads/bc_meio_ambiente/meio_03.pdf>. Acesso 18 mai. 2013.

CUNHA, J. M. P.; ARANHA, V. Migração em São Paulo - Região de Governo de Presidente Prudente. NEPO: UNICAMP, 1992. Disponível em:

<http://www.nepo.unicamp.br/textos/publicacoes/textos_nepo/textos_nepo_23.pdf>. Acesso em: 01 abr. 2013.

DUNDES, A.C. O poder local e a indústria: uma análise do discurso desenvolvimentista prudentino. In: SPÓSITO, M. E. B. (Org). Textos e contextos para leitura geográfica de uma cidade média. Presidente Prudente: UNESP/ FCT, 2001.

FOGLIA, E.; MATHIAS, P. Em uma hora, Prudente registra $25 \mathrm{~mm}$ de chuva e ventos a $40 \mathrm{~km} / \mathrm{h}$. Disponível em:< http://www.ifronteira.com/mobile-noticia-47124>. Acesso em: 08 jun. 2013.

HONDA, S. C. A. L. Habitação de Baixa Renda como Produto do Capital: o Programa de Arrendamento Residencial (PAR) em Presidente Prudente-SP. São Paulo: UPM, 2011 (Tese de Doutorado).

MUSEU DE PRESIDENTE PRUDENTE. Acervo/ Histórico Municipal. Disponível em: <http://museu.presidenteprudente.sp.gov.br/historiapp.php>. Acesso em: 05 mar. 2013. 
PREFEITURA DE PRESIDENTE PRUDENTE, 2007. Notícias/ Chuvas provocam danos no Parque do Povo. Disponível em:< http://www.presidenteprudente.sp.gov.br/site/noticias. $x$ html?cod=532>. Acesso em: 06 jun. 2013.

SILVA, Maria José Martinelli. O Parque do povo em Presidente Prudente - SP: a lógica da intervenção do poder público local no processo de (re)estruturação do espaço urbano. 1994. 152 f. Dissertação (Mestrado em Geografia) - Faculdade de Ciências e Tecnologia, UNESP. Presidente Prudente.

SPTV-2. Chuva alaga novamente o Parque do Povo em Prudente. Disponível em:< http://www.ifronteira.com/noticia-presidenteprudente-34596>. Acesso em: 06 jun. 2013.

VAZ, R. As precipitações extremas e inundações em áreas de fundos de vales em Presidente Prudente :um estudo sobre o Parque do Povo e Prudenshopping. 1999, 66 folhas. Categoria (TCC). Universidade do Estado de São Paulo, FCT/UNESP. Presidente Prudente. 